\title{
Compressive Sampling untuk Sinyal Beat Radar Cuaca via Discrete Cosine Transform (DCT)
}

\author{
RITA PURNAMASARI'1, ANDRIYAN BAYU SUKSMONO²
}

\author{
${ }^{1}$ Telkom University \\ 2Institut Teknologi Bandung \\ Email : ritapurnamasari@telkomuniversity.ac.id
}

Received 7 Januari 2019 | Revised 30 Januari 2019 | Accepted 24 Maret 2019

\begin{abstract}
ABSTRAK
Compressive sampling (CS) merupakan metode baru yang memungkinkan proses pengambilan sampel dan kompresi dilakukan secara bersamaan sehingga dapat mempercepat waktu komputasi sekaligus memperkecil bandwidth saat dilewatkan pada media transmisi. Salah satu cara agar CS dapat bekerja secara optimal adalah jika sinyal yang akan diolah memiliki tingkat sparsitas yang tinggi. Pada makalah ini, mengusulkan algoritma Discrete Cosine Transform (DCT) sebagai metode transformasi sparsitas untuk sinyal beat radar cuaca IWarp. Sinyal beat menjadi sparse setelah direpresentasikan pada domain frekuensi, sehingga dapat mengambil sampelnya secara acak dan akhirnya mendapatkan sekumpulan sinyal sampel yang telah berukuran lebih kecil daripada sinyal beat radar awal. Pada penelitian ini menggunakan $\ell_{1}$-magic untuk melakukan rekonstruksi dari sinyal yang telah terkompresi tersebut. Simulasi numerik menunjukkan bahwa algoritma yang diusulkan berada pada performansi yang baik dengan rata-rata Peak Signal Noise to Ratio (PSNR) sebesar 15,17 dB.
\end{abstract}

Kata kunci: CS, radar cuaca, sparsitas, DCT, rekonstruksi $\ell_{1}$

\begin{abstract}
Compressive sampling (CS) is a new method that allows sampling and compression to be carried out simultaneously so that it can increase the computing time and reduce bandwidth while passed on the transmission media. One way for CS to work optimally is if the signal to be processed has a high sparsity level. In this paper we propose the Discrete Cosine Transform (DCT) algorithm as a sparsity transformation method for IWarp weather radar beat signals. The beat signal becomes sparse after being represented in the frequency domain, so this can randomly take samples and finally get a set of sample signals that are smaller than the initial radar beat signal. In this reasearch, use $\ell_{1}$-magic to reconstruct the compressed signal. Numerical simulations show that the proposed algorithm is in good performance with an average Peak Signal Noise to Ratio (PSNR) of $15.17 d B$
\end{abstract}

Keywords: $C S$, weather radar, sparsity, DCT, $\ell_{1}$-reconstruction 


\section{PENDAHULUAN}

Radar cuaca merupakan salah satu jenis radar yang digunakan untuk mendeteksi intensitas curah hujan, arah pergerakannya, hingga memperkirakan jenisnya (seperti hujan salju, hujan es, maupun hanya hujan gerimis dengan intensitas rendah). Seiring dengan perkembangan zaman, radar cuaca dituntut untuk memberikan informasi mengenai kondisi cuaca di angkasa secara real time dan akurat. Untuk mendapatkan hasil-hasil tersebut, radar cuaca melakukan pengambilan banyak sampel data jarak dengan pengulangan pulsa dalam setiap detik sehingga menghasilkan data dalam domain waktu yang berjumlah besar. Oleh karena itu, pada perangkat radar cuaca harus tersedia bandwidth media transmisi dalam kapasitas yang besar. Selain itu perangkat pemroses pada radar cuaca juga harus dirancang lebih canggih agar dapat mengimbangi waktu komputasi untuk data dengan jumlah besar. Beberapa langkah tersebut membutuhkan biaya yang sangat mahal, sehingga alternatif lain untuk mengurangi beban volume data adalah dengan melakukan teknik kompresi pada saat akuisisi data.

Akuisi data adalah proses pengambilan sampel sinyal dengan cara mengukur kondisi fisik dari data dan kemudian mengubahnya menjadi data-data numerik dijital sehingga dapat direkayasa oleh komputer. Pada proses akuisisi data secara konvensional, frekuensi pengambilan sampel haruslah dua kali frekuensi sinyal menurut (Shannon, 1949) dan (Nyquist, 1928). Hal ini dilakukan agar pada saat rekontruksi sinyal keluaran yang dihasilkan oleh sistem mirip dengan sinyal masukan atau dengan kata lain memiliki akurasi yang tinggi.

Akhir-akhir ini muncul metode akuisisi data baru yang berbeda dengan metode konvensional sebelumnya, dimana frekuensi pengambilan sampel dapat jauh lebih sedikit daripada metode sebelumnya. Metode baru ini disebut sebagai Compressive Sampling (CS) (Donoho, 2006). CS adalah sebuah metode yang bisa membantu proses akuisisi menjadi lebih cepat karena hanya mengambil beberapa sampel sinyal yang memiliki koefisien yang tinggi dengan syarat bahwa sinyal harus sparse dan inkoheren terhadap kamus basisnya (Candès \& Wakin, 2008). Pada teknik CS, pengambilan sampel dan kompresi data dilakukan dalam satu waktu sekaligus sedangkan pada pemrosesan sinyal konvensional, pengambilan sampel dilakukan dengan metode Shannon-Nyquist kemudian setelah itu dilakukan kompresi. Artinya bahwa dengan menggunakan CS dapat mempercepat waktu akuisisi data dibandingan metode konvensional sebelumnya.

Penelitian awal yang mengusulkan metode CS untuk aplikasi pada radar dipublikasikan oleh (Baraniuk \& Steeghs, 2007). Penelitian tersebut membuktikan bahwa CS dapat menggantikan proses pulse compression pada aplikasi radar Synthetic Aperture Radar (SAR). Namun dalam penelitian ini obyek yang diteliti berupa target titik, sedangkan cuaca merupakan sekumpulan target titik yang berbentuk volume. Hasil penelitian pada makalah tersebut menunjukkan bahwa dengan teknik CS dapat mengurangi kebutuhan bandwidth pada saat proses pengambilan sampel sehingga matched filter untuk pulse compression tidak diperlukan lagi. Aplikasi CS untuk radar lainnya juga pernah dikembangkan pada radar jenis Stepped Frequency Continuous Wave (SFCW) untuk radar pencitra SAR (Suksmono, 2014) dan Radar Multiple Input Multiple Output (MIMO) (Sajjadieh \& Asif, 2017).

Pada makalah (Mishra, Kruger, \& Krajewski, 2014) diusulkan penelitian CS pada radar cuaca dengan menganggap bahwa data cuaca tidak dapat direpresentasikan secara sparse pada domain waktu maupun frekuensi, sehingga pengubahan data menjadi sparse dilakukan dengan cara mendekomposisi data dan merepresentasikannya dengan menggunakan matriks 
low rank. Sedangkan teknik rekonstruksi sinyal menggunakan teknik Singular Value Thresholding (SVT). Dalam penelitian ini keberhasilan rekonstruksi sinyal radar cuaca sangat baik walaupun $75 \%$ dari nilai singular datanya dihilangkan, namun penelitian ini belum membahas pengaruh dari noise dan ground clutter terhadap sistem radar cuaca.

Makalah lainnya yaitu (Kawami, et al., 2016) dan (Kawami, et al., 2017) juga telah mengusulkan metode CS untuk kompresi radar cuaca jenis Phased Array Weather Radar (PAWR). Pada penelitian pertama, penulis meneliti kompresi radar cuaca untuk 2 dimensi sedangkan pada makalah kedua, kompresi radar cuaca dilakukan untuk 3 dimensi. Pengambilan sampel dilakukan dengan dua cara, yaitu secara seragam maupun secara acak. Transformasi sparsitas dilakukan dengan menggunakan teknik DCT dan teknik rekonstruksi dengan menggunakan minimum Total Variance. Keunggulan dari penelitian ini adalah sistem mampu meminimalisasi kesalahan hingga 4\%. Namun sistem ini masih memiliki kelemahan dalam hal waktu komputasi yang lebih lama dibandingkan dengan penelitian-penelitian lain sebelumnya. Penulis yang sama pada paper terbarunya (Kawami, et al., 2017) mengusulkan metode yang hampir sama dengan penelitian yang sebelumnya namun terdapat tambahan blok optimasi pada tahap rekonstruksi sinyal dengan cara melakukan segmentasi hasil kompresi sehingga waktu yang dibutuhkan saat rekonstruksi lebih cepat daripada hasil penelitian penulis sebelumnya.

Pada makalah (Purnamasari, Suksmono, Edward, \& Zakia, 2018), penulis mengusulkan metode CS untuk mengkompresi sinyal beat pada radar cuaca dan merekonstruksinya dengan menggunakan algoritma basis pursuit dan Orthogonal Matching Pursuit (OMP). Pada penelitian tersebut, representasi sinyal pada basis sparse dilakukan dengan metode DCT dan Fast Fourier Transform (FFT). Hal ini dilakukan dengan tujuan untuk mengurangi kompleksitas sistem saat melakukan pengolahan sinyal radar cuaca untuk mengestimasi produk radar cuaca utama seperti reflektifitas. Berdasarkan hasil simulasi diperoleh kesimpulan bahwa rekonstruksi dengan menggunakan algoritma OMP lebih baik daripada basis pursuit walaupun memerlukan waktu komputasi yang lebih lama.

Pada makalah ini, mengusulkan metode CS dengan menggunakan DCT sebagai metode transformasi sparsitas dan rekonstruksi $\ell_{1}$ pada data rill sinyal beat radar IWarp. Penelitian CS untuk radar cuaca dengan metode transformasi sparsitas menggunakan DCT sudah pernah dilakukan oleh (Kawami, et al., 2016) namun teknik rekonstruksi yang mereka gunakan adalah dengan mencari nilai minimum Total Variance, sedangkan pada makalah ini mengusulkan teknik rekonstruksi dengan menggunakan minimasi $\ell_{1}$. Teknik $\ell_{1}$ sebagai bagian dari teknik basis pursuit yang digunakan pada makalah ini karena memiliki tingkat kecepatan yang lebih tinggi berdasarkan hasil penelitian pada makalah sebelumnya (Purnamasari, Suksmono, Edward, \& Zakia, 2018). Penelitian lain yang mirip telah diusulkan oleh makalah (Shimamura, et al., 2016) dengan menerapkan teknik DCT sebagai transformasi sparsitas dan $\ell_{1}$ sebagai teknik rekonstruksinya untuk radar cuaca, namun jenis radar yang digunakan adalah jenis radar Phased Array Weather Radar (PAWR), sedangkan pada makalah ini menggunakan radar IWarp yang merupakan jenis radar Frequency Modulated Continuous Wave (FMCW). Berbeda antara PAWR dengan FMCW dimana pada PAWR teknik sparsitas ditujukan untuk mengkompresi sudut elevasi kedatangan sinyal sedangkan pada FMCW teknik sparsitas ditujukan untuk mengkompresi jarak kedatangan sinyal. Radar FMCW memberikan informasi jarak target pada domain frekuensi. Oleh sebab itulah, pada makalah ini mengusulkan teknik DCT karena dianggap dapat merepresentasikan sinyal real radar IWarp pada kondisi yang sparse di domain frekuensi karena pada domain waktu sendiri sinyal real radar ini memiliki tingkat sparsitas 
yang rendah. Dengan asumsi kondisi sparsitas yang tinggi pada domain frekuensi, dapat mengkompresi jarak dengan baik dan kemudian merekonstruksikannya kembali.

Terdapat tiga tahapan utama pada metode CS ini yaitu transformasi sparsitas, pengambilan sampel dan rekonstruksi. Pada proses transformasi sparsitas, sinyal beat radar dirubah menjadi bentuk yang lebih sparse pada domain frekuensi dengan menggunakan teknik DCT. Kemudian proses pengambilan sampel dilakukan secara acak dengan menggunakan matriks pengukuran yang berbeda-beda. Setelah itu proses terakhir adalah melakukan rekonstruksi untuk mendapatkan sinyal beat radar kembali. Algoritma rekonstruksi yang digunakan pada penelitian ini adalah pendekatan $\ell_{1}$. Penjelasan proses tersebut dalam bab maupun sub-bab selanjutnya.

\subsection{Sparsitas Sinyal}

Sinyal yang sparse merupakan salah satu syarat untuk keberhasilan rekonstruksi pada teknik CS. Umumnya tidak semua sampel sinyal yang diambil memiliki representasi sparse, sehingga yang harus dilakukan adalah dengan mengubah representasi sinyal tersebut ke dalam domain lainnya sehingga berbentuk sparse. Teknik yang biasanya digunakan untuk membuat sinyal menjadi sparse adalah DCT, FFT, dan Discrete Wavelet Transform (DWT). Namun dikarenakan data IWarp yang dieksplorasi dalam makalah ini merupakan bilangan riil dengan tingkat sparsitas yang rendah di domain waktu, maka diusulkan metode DCT sebagai teknik transformasi sparsitasnya. DCT merupakan transformasi Fourier yang hanya mengoperasikan bilangan riil. Dengan asumsi tersebut, dibuktikan bahwa DCT dapat mengubah data riil radar IWarp dari domain waktu ke domain frekuensi sehingga tingkat sparsitasnya menjadi tinggi.

Persamaan Umum dari DCT dan Inverse DCT (Strang, 2006) terdapat pada Persamaan (1) dan Persamaan (2) berikut ini

$$
X(k)=e(k) \sum_{n=0}^{N-1} x(n) \cos \left[\frac{(2 n+1) \pi k}{2 N}\right], \text { dengan } k=0,1, \ldots, N-1,
$$

untuk Inverse Discrete Cosine Transform (IDCT)

$$
\begin{gathered}
x(n)=\frac{2}{N} \sum_{k=0}^{N-1} e(k) X(k) \cos \left[\frac{(2 n+1) \pi k}{2 N}\right], \text { dengan } n=0,1, \ldots, N-1, \\
e(k)=\left\{\begin{array}{c}
\frac{1}{\sqrt{2}}, \quad \text { jika } k=0 \\
1, \text { untuk yang lainnya. }
\end{array}\right.
\end{gathered}
$$

\subsection{Matriks Pengukuran}

Matriks pengukuran merupakan bagian penting di dalam teknik CS. Matriks ini dibangkitkan secara acak dan berfungsi untuk mengambil sampel dari sinyal beat radar. Jika sinyal beat awal dimisalkan dengan $x$ memiliki ukuran $n \times 1$ dan matriks pengukuran dimisalkan sebagai matriks A berukuran $M \times N$, dimana ukuran $M \ll N$, maka saat ini ukuran sinyal yang telah terkompresi yaitu Y menjadi $m \times 1$, secara matematis dipresentasikan pada Persamaan (3) berikut ini:

$$
Y=A \cdot x .
$$


Ilustrasi CS secara sederhana dijelaskan pada Gambar 1 berikut ini
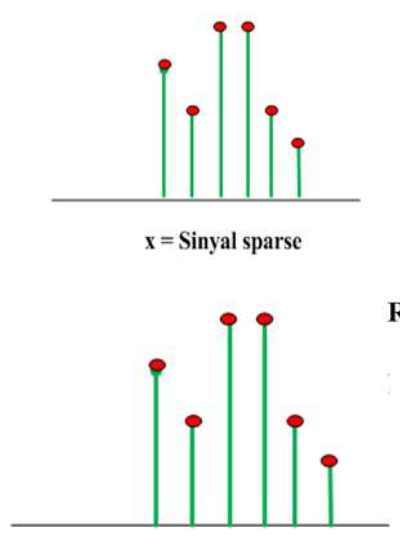

$x$

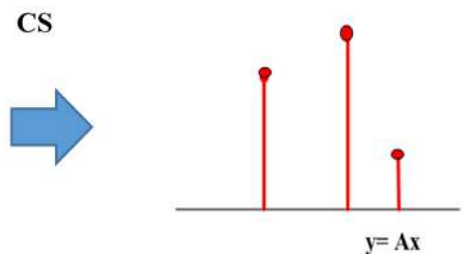

Rekonstruksi

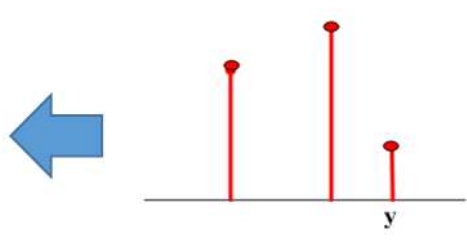

Gambar 1. Ilustrasi Sederhana CS

\section{$1.3 \quad$ Restricted Isometry Property (RIP)}

Untuk menentukan matrik pengukuran A sedemikian sehingga sinyal asli $x$ dapat dikembalikan dari pengukuran Y (Candès Justin, Romberg, \& Tao, 2006) menurunkan syarat dari matriks pengukuran A yang disebut dengan Restricted Isometry Property (RIP). Suatu matriks pengukuran A dikatakan bersifat RIP jika memenuhi kondisi:

$$
\left(1-\delta_{s}\right)|x|_{2} \leq|A x|_{2} \leq\left(1+\delta_{s}\right)|x|_{2},
$$

dimana $\delta_{s}$ adalah suatu bilangan yang sangat kecil. Sifat RIP ini secara geometris menyatakan bahwa norm orde- 2 dari vektor $x$ sebelum dan setelah transfromasi tidak berubah banyak nilainya.

\subsection{Rekonstruksi}

Pada sisi radar penerima, sinyal asli dari radar $x$ yang telah terkompresi melalui persamaan linier $y=A \cdot x$, harus dapat diperoleh kembali. Salah satu pendekatan yang dilakukan adalah sebagai berikut

$$
x=\operatorname{argmin}|x|_{*} \text { subject to } A \cdot x=Y \text {. }
$$

Penyelesaian dengan Persamaan (5) adalah dengan cara mencari semua kemungkinan nilai $x$ paling minimum.

\subsection{Parameter Kinerja}

\subsubsection{Peak Signal to Noise Ratio (PSNR)}

PSNR merupakan salah satu metode pengukuran objektif dengan cara membandingkan antara nilai maksimum sinyal yang diukur terhadap sinyal deraunya. Satuan dari PSNR umumnya adalah decible (dB). PSNR digunakan untuk mengetahui perbandingan kualitas sinyal beat terekonstruksi terhadap sinyal beat radar cuaca asli. Persamaan yang digunakan untuk perhitungan PSNR adalah (Milinkovic \& Petric, 2018) 


$$
P S N R=10 \log _{10} \frac{C_{\max }}{\sqrt{\frac{1}{N} \sum_{i=0}^{N-1}\left(x_{r e k}-x_{a s l i}\right)^{2}}}
$$

Dimana $N$ adalah panjang sinyal beat yang dalam penelitian ini adalah $512, x_{\text {asli }}$ adalah sinyal beat radar dan $x_{\text {rek }}$ adalah sinyal beat hasil rekonstruksi, dan $c_{\text {max }}$ merupakan nilai maksimum dari sinyal beat radar.

\subsubsection{Root Mean Square Error (RMSE)}

Seperti halnya PSNR, RMSE juga merupakan pengukuran kualitas sinyal secara obyektif. RMSE digunakan untuk mengetahui kualitas dari suatu teknik rekonstruksi sinyal dengan cara mencari nilai akar kuadrat dari selisih antara sinyal hasil rekonstruksi $\left(x_{\text {rek }}\right)$ dengan sinyal asli $\left(x_{a s l i}\right)$ yang dirata-ratakan sepanjang sinyal $(N)$. Nilai RMSE yang kecil memiliki arti bahwa kemiripan sinyal hasil rekonstruksi dengan sinyal asli semakin besar. Sebaliknya jika nilai RMSE besar maka kemiripan dengan sinyal asli sangat buruk. Persamaan (7) berikut ini menunjukkan formula perhitungan RMSE (Reyes, Hilaire, Paul, \& Mecklenbr"auker, 2010)

$$
R M S E=\sqrt{\frac{1}{N} \sum_{i=0}^{N-1}\left(x_{r e k}-x_{a s l i}\right)^{2}}
$$

\section{METODOLOGI}

Penelitian ini bertujuan untuk mengimplementasikan teknik CS pada sinyal radar cuaca IWarp dengan menggunakan transformasi sparsitas DCT dan rekonstruksi $\ell_{1}$-magic, yang dapat mempercepat proses akuisisi sinyal. Posisi aplikasi CS dalam teknologi radar cuaca sendiri dapat diilutrasikan pada Gambar 2 berikut ini. Data yang didapatkan radar dalam waktu tertentu dikompresi agar bandwidth yang dibutuhkan saat perjalanan sinyal dari radar penerima ke stasiun pematau cuaca melewati media transmisi berkurang.

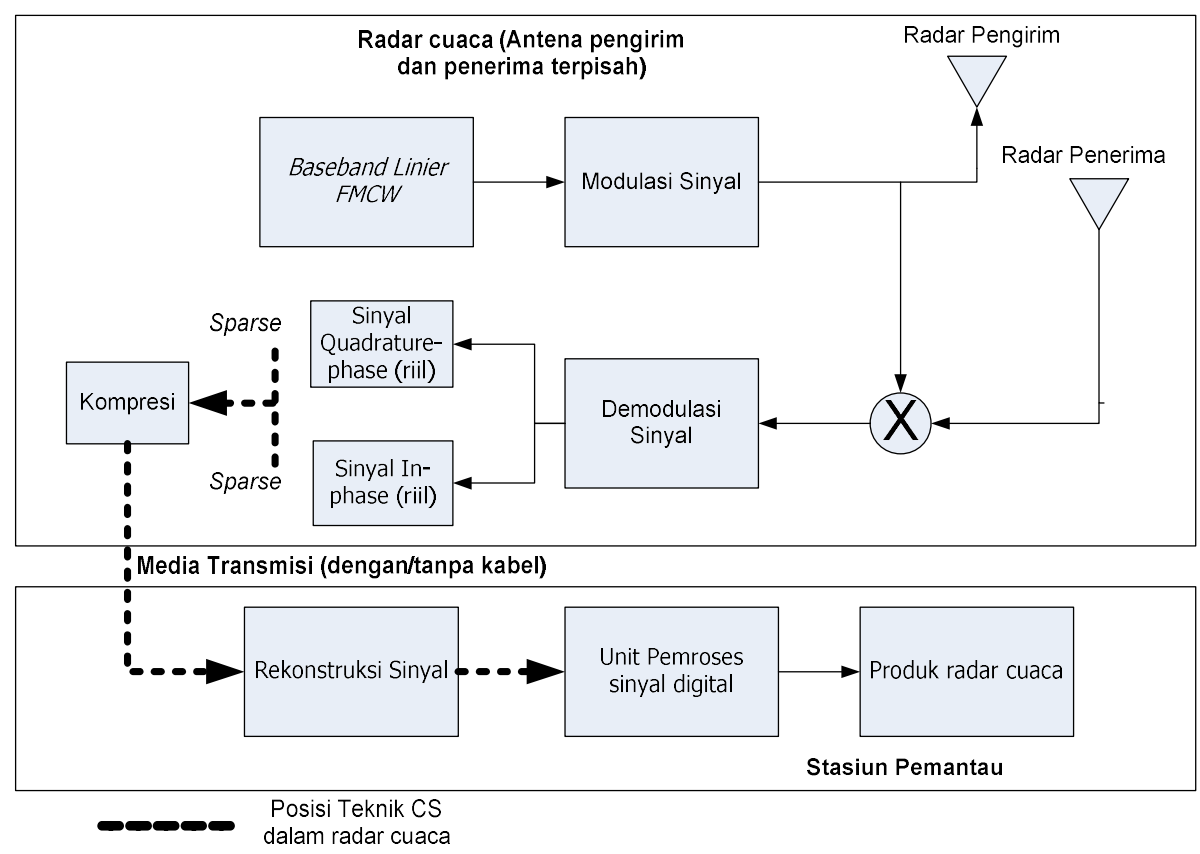

Gambar 2. Implementasi CS untuk Akuisisi Data pada Radar Cuaca 
Agar tujuan tersebut dapat dicapai, metodologi dalam penelitian ini dibagi menjadi beberapa tahap:

1. Pengumpulan Data

Data yang diolah merupakan data riil keluaran dari salah satu lengan modulator pada radar cuaca IWarp yang biasa dikenal sebagai sinyal beat radar.

2. Perancangan Sistem

Terdapat tiga buah skema rancangan yang digunakan yaitu proses transformasi sparsitas (1), proses pengambilan sampel dan proses rekonstruksi (3). Proses transformasi sparsitas bertujuan untuk mengubah representasi dari sinyal beat radar IWarp menjadi bentuk yang sparse. Proses pengambilan sampel bertujuan untuk mengambil informasi penting dari sinyal. Proses pengambilan tersebut dilakukan secara acak dengan cara terlebih dahulu membangkitkan matriks pengukuran secara acak dengan ukuran $M \times N$. Proses terakhir adalah melakukan rekonstruksi sinyal (2) (5). Proses ini bertujuan untuk mengembalikan sinyal beat radar yang telah terkompresi sebelumnya.

Deskripsi sistem usulan di atas dijelaskan pada Gambar 3 berikut ini:

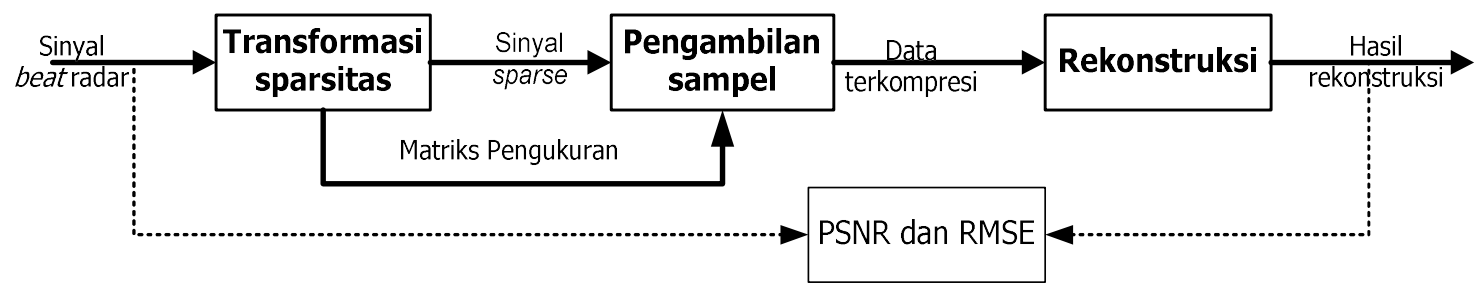

Gambar 3. Blok Perancangan Sistem

Tahapan transformasi sparsitas diilustrasikan sebagai berikut:

Tahap 1 : Membaca sinyal beat radar asli $\left(x_{a s l i}\right)$ yang berukuran $N \times 1$.

Tahap 2: Melakukan transformasi sparsitas pada sinyal beat radar dengan cara mengalikan sinyal beat radar dengan matriks ortogonal DCT sehingga didapatkan sinyal $x$ yang sparse.

Proses transformasi sparsitas pada penelitian ini digambarkan pada Gambar 4 berikut ini

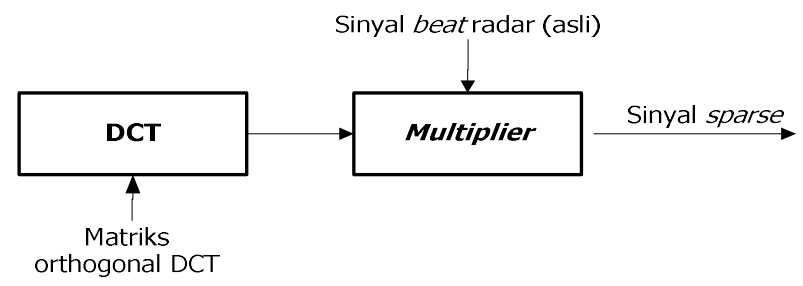

Gambar 4. Diagram Blok Transformasi Sparsitas (1)

Tahapan untuk proses pengambilan sampel adalah sebagai berikut ini:

Tahap 1 : Mempersiapkan sinyal masukan. Sinyal ini sudah direpresentasikan ke dalam domain frekuensi dan memiliki sifat sparse. Sifat sparse yang dimaksud adalah memiliki koefisien signifikan yang lebih kecil daripada koefisien nol-nya. Ukuran panjang sinyal ini setelah dirubah pada domain frekuensi adalah masih sama dengan sinyal asli yaitu sepanjang $N \times 1$.

Tahap 2 : Membangkitkan matriks pengukuran A yang memiliki ukuran $M \times N$. Ukuran $M$ harus lebih kecil daripada $N$. Ukuran $M \times N$ pada penelitian ini bervariasi mulai 
dari (409 x 512), (307 x 512), (256 x 512), (204 x 512), dan (153 x 512). Perbandingan antara $M$ dan $N$ biasa disebut sebagai rasio kompresi.

Tahap 3 : Lakukan normalisasi pada matriks A agar didapatkan matriks A yang ortonormal.

Tahap 4 : Lakukan proses pengambilan sampel dengan cara mengalikan matriks pengukuran A dengan matriks sinyal yang sudah sparse pada domain frekuensi. Keluaran dari blok ini adalah sinyal sampel dengan ukuran yang lebih kecil daripada sinyal masukan. Hal ini menandakan bahwa selain sampel sudah terambil juga terkompresi karena panjang sinyal menjadi berukuran lebih kecil $(M \ll N)$. Pada blok ini juga dilakukan pengujian pengaruh rasio kompresi terhadap performansi sistem. Rasio kompresi yang diujikan pada metode yang diusulkan ini adalah $20 \%, 30 \%, 50 \%$, $60 \%$ dan $70 \%$.

Diagram blok proses pengambilan sampel dan proses kompresi ditunjukkan pada Gambar 5 di bawah ini

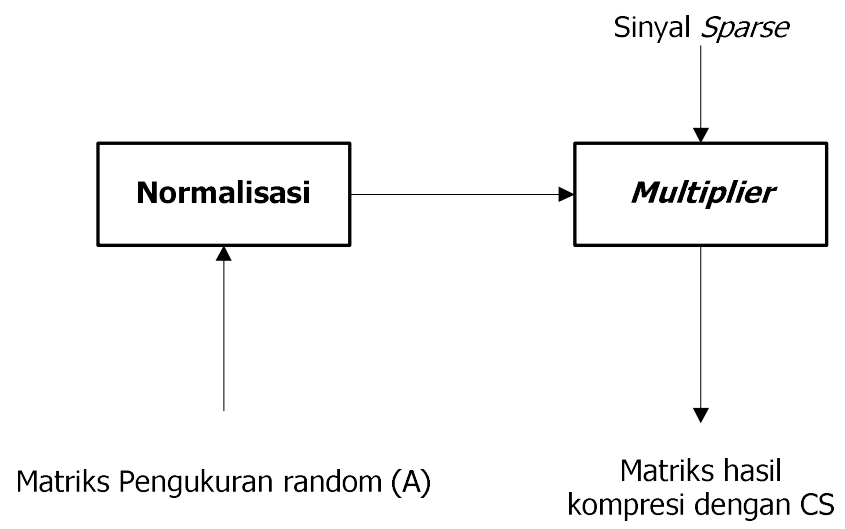

\section{Gambar 5. Diagram Blok Proses Pengambilan Sampel dan Proses Kompresi (3)}

Tahapan proses Rekonstruksi adalah sebagai berikut ini:

Tahap 1: Merekonstruksi sinyal dengan menggunakan pemrograman $\ell_{1}$-magic sebagai wakil dari basis pursuit dan Orthogonal Matching Pursuit (OMP) sebagai wakil dari matching pursuit.

Tahap 2: Matriks pengukuran A dan pseudo inverse dari matriks hasil kompresi menjadi kamus dan pengetahuan awal untuk mendapatkan sinyal asli.

Tahap 3: Proses pengubahan sinyal dari domain frekuensi menjadi domain waktu kembali dengan menggunakan metode IDCT

Tahap 4: Proses terakhir adalah melakukan normalisasi sinyal hasil rekonstruksi dan sinyal asli untuk perhitungan akurasi

Diagram blok proses Rekonstruksi terdapat pada Gambar 6 berikut ini

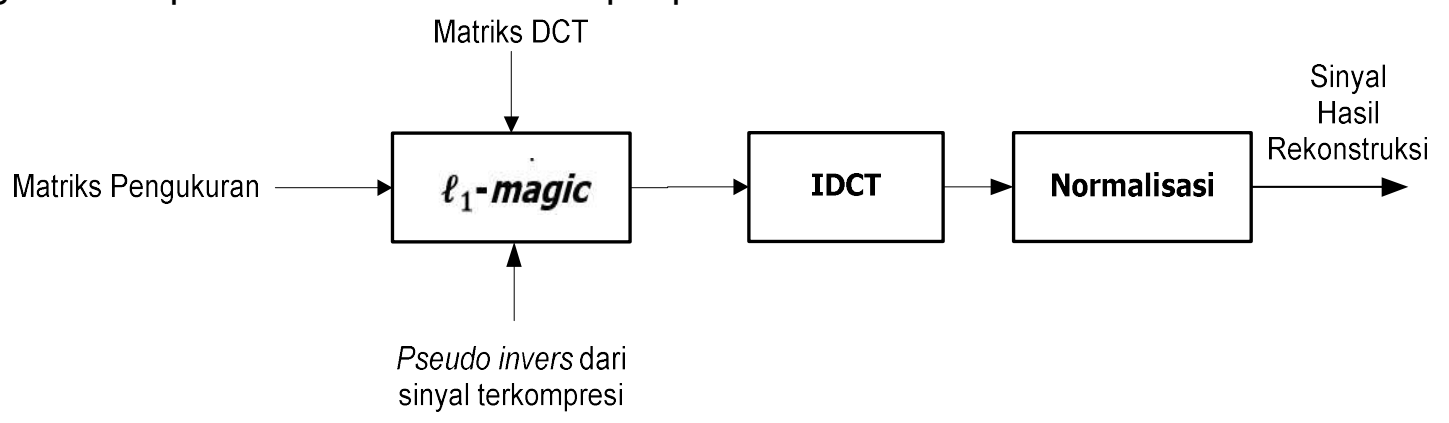

Gambar 6. Diagram Blok Rekonstruksi (2)(5) 
Tahapan akhir adalah melakukan analisis performansi metode CS untuk sinyal beat radar cuaca yaitu dengan menggunakan parameter PSNR (6), RMSE (7), dan waktu komputasi.

\section{HASIL DAN DISKUSI}

Pada bagian ini menunjukkan hasil simulasi dan analisis numerik dari metode yang diusulkan berupa perubahan PSNR, RMSE dan waktu komputasi. Pengujian yang dilaporkan pada bagian ini dengan mengubah beberapa paramater masukan seperti rasio kompresi dan algoritma dasar rekonstruksi.

Gambar 7 berikut ini merupakan sinyal beat radar cuaca yang memiliki panjang 512 bin dengan amplitudo berada pada rentang $-3 \times 10^{4}$ hingga $3 \times 10^{4}$ volt. Sinyal beat ini diambil dari data riil radar cuaca IWarp. Gambar 7(a) merupakan sinyal keluaran dari modulator lengan inphase dengan polarisasi arah vertikal pada domain waktu. Sedangkan Gambar 7(b) merupakan hasil transformasi sparsitas dengan menggunakan transformasi DCT. Pada domain waktu sinyal terlihat tidak sparse karena memiliki koefisien signifikan di sepanjang range bin. Sedangkan pada domain Fourier, sinyal terlihat sparse dengan koefisien signifikan jauh lebih berkurang dibandingkan dengan kondisi pada domain waktu.

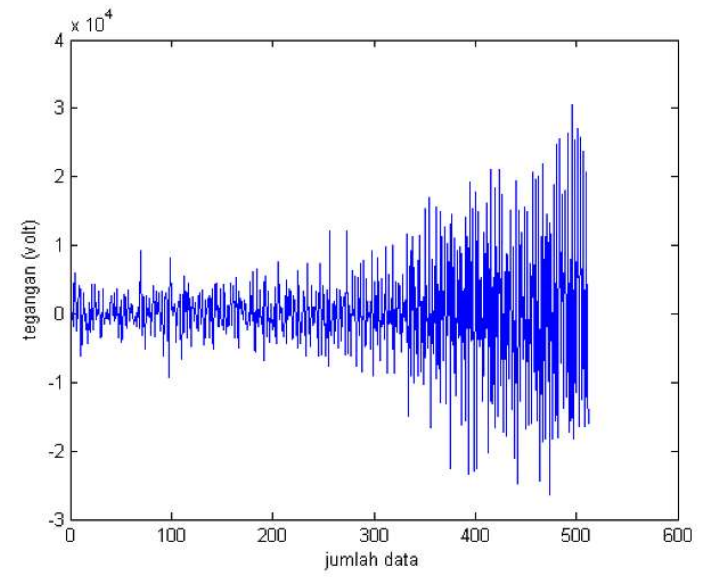

(a)

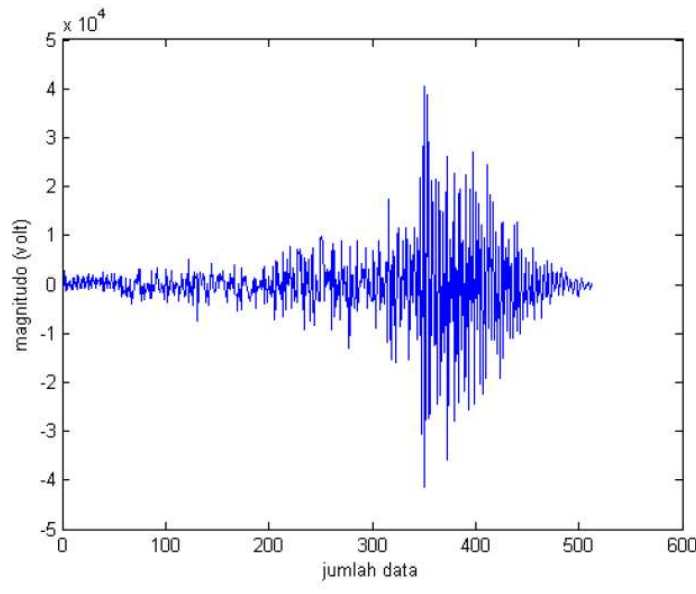

(b)

Gambar 7. Sinyal Beat Radar Cuaca Iwarp pada Domain (a) waktu dan (b) Fourier

Gambar 8 di bawah ini menunjukkan hasil rekonstruksi dengan menggunakan metode $\ell_{1}$ via transformasi sparsitas DCT dengan rasio kompresi yang berbeda yaitu $20 \%$ pada Gambar 8(a) dan 80 \% pada Gambar 8(b). Pada data ke-400 sampai dengan 410 dilakukan perbesaran agar dapat diamati lebih detil contoh hasil rekonstruksinya. Dari hasil simulasi pada Gambar 8(a) tersebut kita mengetahui bahwa sinyal $\left(x_{r e k}\right)$ hasil rekonstruksi dapat mengikuti pola dari sinyal beat radar yang asli $\left(x_{\text {asli }}\right)$, walaupun jika dilihat secara keseluruhan terdapat ketidaksamaan di beberapa titik antara sinyal hasil rekonstruksi terhadap sinyal asli. Sedangkan pada Gambar 8(b) memperlihatkan hasil rekonstruksi sinyal beat yang buruk karena pola sinyal hasil rekonstruksi sangat berbeda dengan pola sinyal beat asli. 


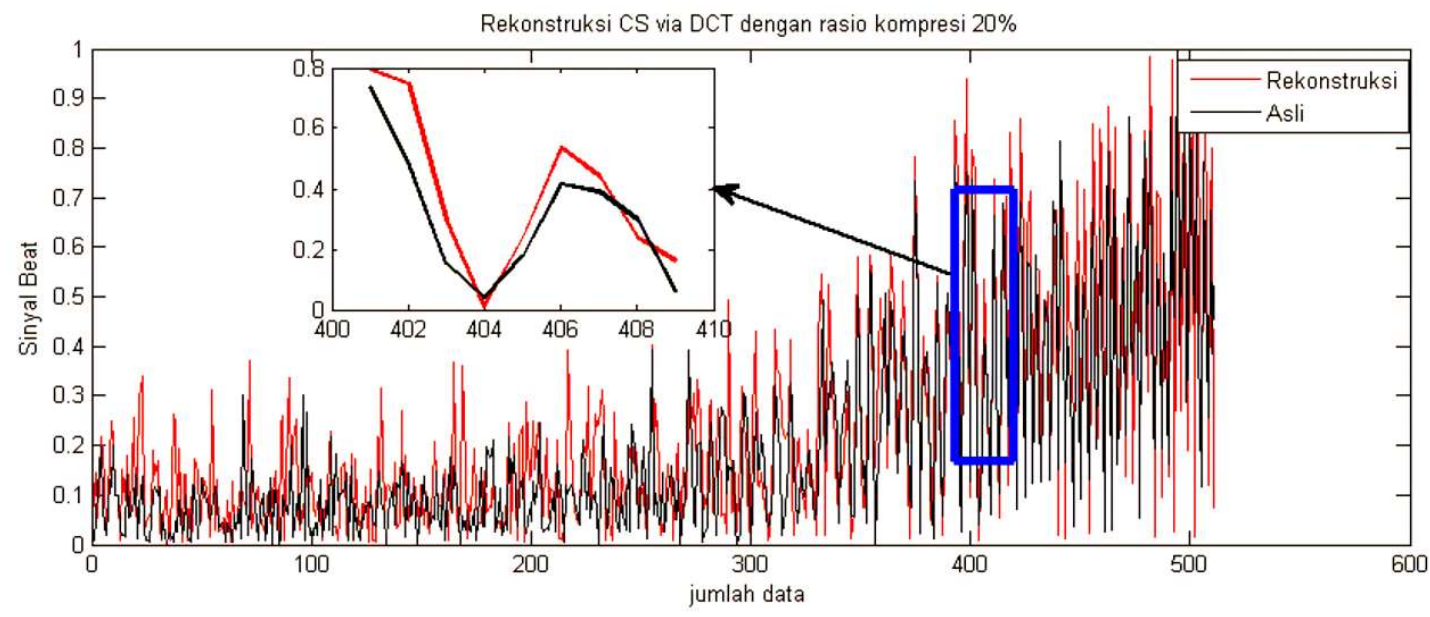

(a)

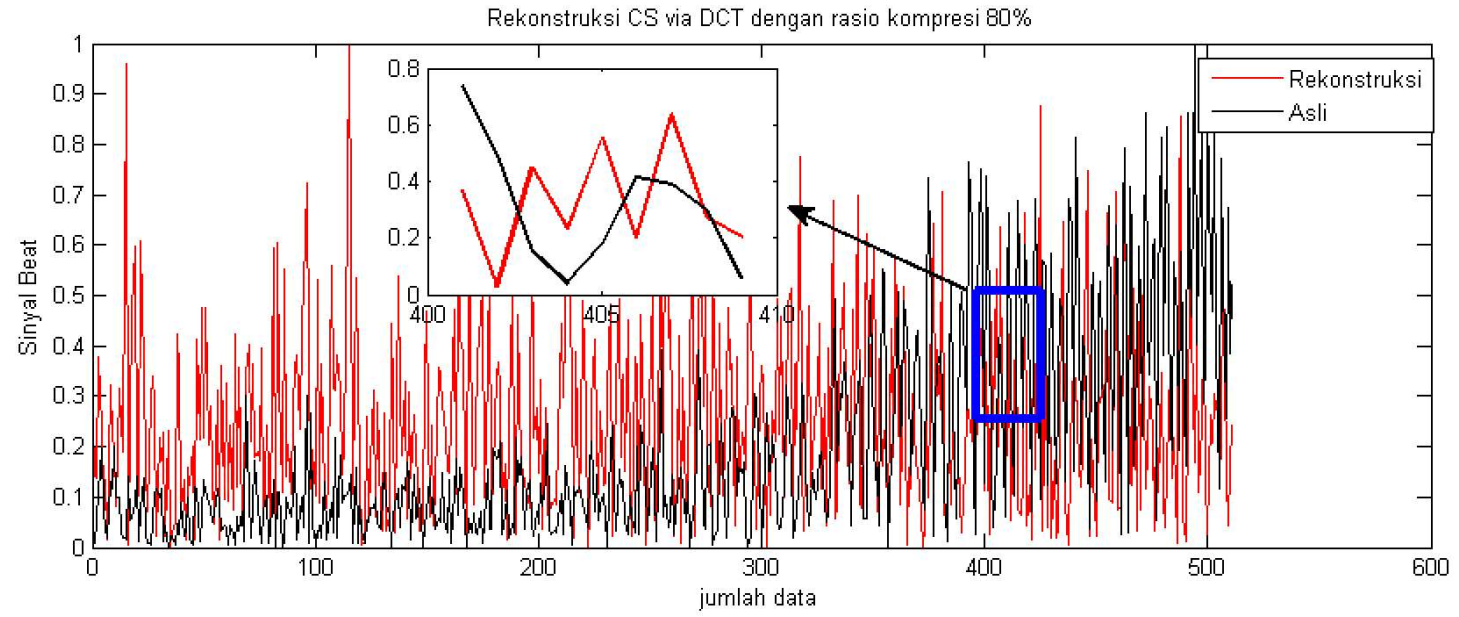

(b)

Gambar 8. Rekonstruksi $\ell_{1}$ via DCT dengan Rasio Kompresi (a) $20 \%$ dan (b) $80 \%$

Hal ini dapat dipahami bahwa pada Gambar 8(a) sinyal diambil sampelnya sebanyak $80 \%$ dari panjang sinyal asli, sedangkan pada Gambar 8(b) sinyal diambil sampelnya sebanyak $20 \%$ dari panjang sinyal asli. Tentu saja hasil terbaik akan diperoleh jika sampel sinyal yang diambil ini berjumlah lebih banyak sehingga lebih akurat, begitupun sebaliknya jika sampel yang diambil sedikit maka sinyal rekonstruksi yang dihasilkan kurang akurat.

Sedangkan Gambar 9 berikut ini ditunjukkan hasil rekonstruksi dengan menggunakan metode Orthogonal Matching Pursuit (OMP) dan transformasi sparsitas DCT dengan rasio kompresi yang berbeda yaitu 20\% pada Gambar 9(a) dan $80 \%$ pada Gambar 9(b). Pada data ke-400 sampai dengan 410 juga dilakukan perbesaran agar dapat kita ketahui pola rekonstruksinya. Dari hasil simulasi pada Gambar 9(a) dapat kita diketahui bahwa sinyal $\left(x_{r e k}\right)$ hasil rekonstruksi mengikuti pola dari sinyal beat radar yang asli $\left(x_{\text {asli }}\right)$. Sedangkan pada Gambar 9(b) memperlihatkan hasil rekonstruksi sinyal beat yang buruk, dikarenakan sinyal hasil rekonstruksi dan sinyal asli berbeda cukup signifikan. 


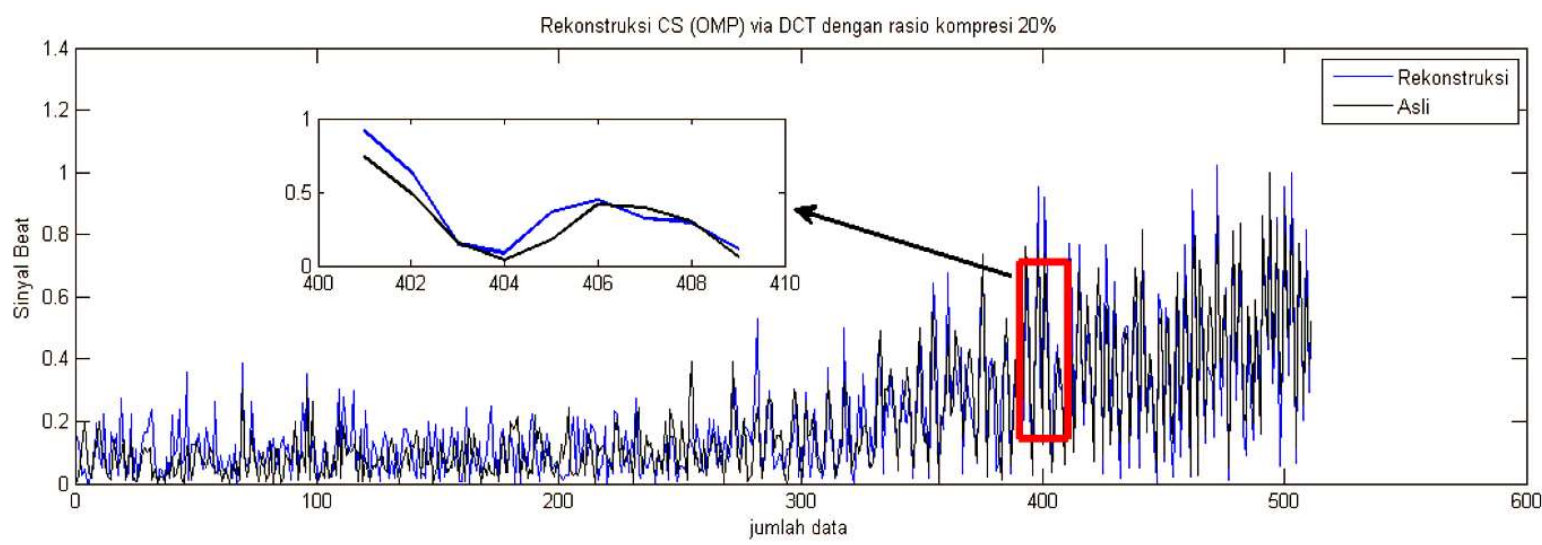

(a)

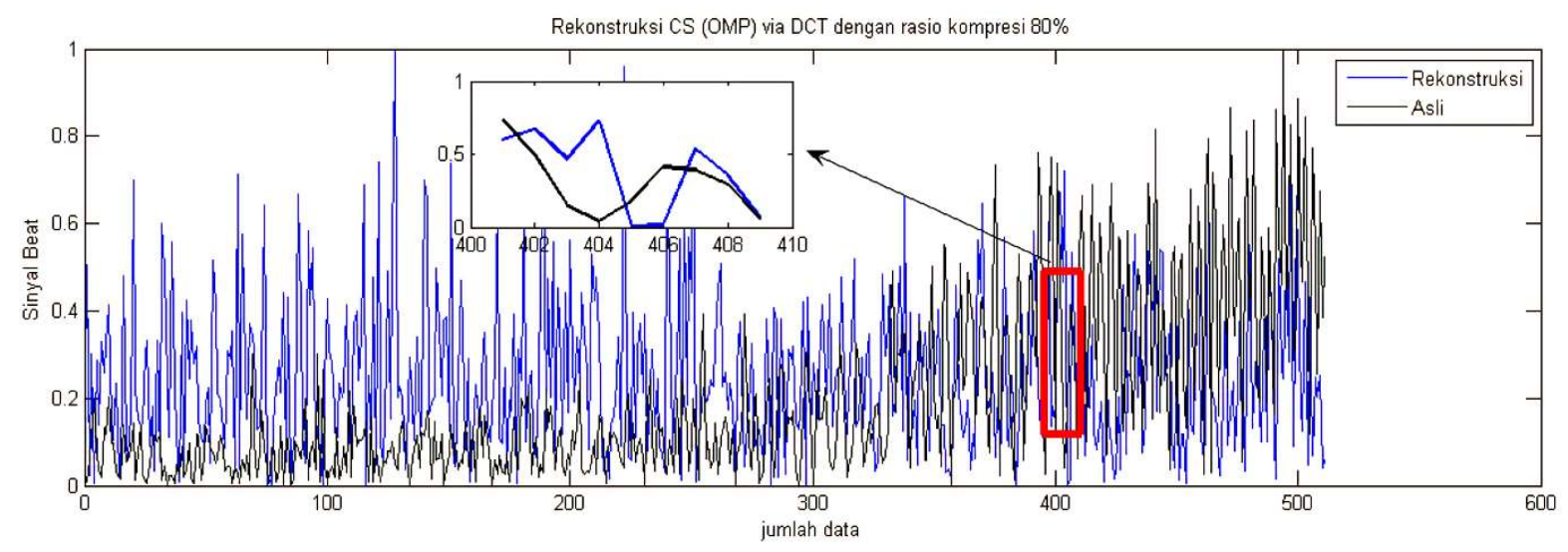

(b)

\section{Gambar 9. Rekonstruksi OMP via DCT dengan Rasio Kompresi (a) $20 \%$ dan (b) $80 \%$}

Setelah melakukan simulasi terhadap rasio kompresi pada Gambar 8 dan 9, kemudian menganalisis hasil numerik grafik hasil dari performansinya seperti yang ditampilkan pada Gambar 10-12. Tabel tersebut menunjukkan bahwa nilai rasio kompresi berpengaruh terhadap PSNR, RMSE dan waktu komputasi. Hasil ini diperoleh dari simulasi rekonstruksi dengan $\ell_{1}$ via DCT. Semakin besar nilai rasio kompresi yang digunakan maka semakin buruk nilai PSNR yang dihasilkan. Begitu juga dengan semakin besarnya rasio kompresi semakin besar nilai RMSE. Rata-rata PSNR yang diperoleh dengan metode yang diusulkan adalah $15.17 \mathrm{~dB}$, untuk rata-rata RMSE-nya adalah 0.182071 .

Selain menggunakan algoritma $\ell_{1}$-magic untuk rekonstruksi sinyal, menggunakan OMP untuk perbandingan performansi. Pada penelitian ini membandingkan kedua algoritma yang berbeda basis: basis pursuit untuk $\ell_{1}$-magic dan matching pursuit untuk OMP. Parameter pengujian seperti rasio kompresi juga diteliti pada simulasi dengan algoritma OMP tersebut. Sebanding dengan hasil simulasi sebelumnya yang menggunakan rekonstruksi $\ell_{1}$-magic, pada hasil simulasi algoritma OMP dengan pengubahan rasio kompresi menunjukkan bahwa semakin besar nilai rasio kompresi yang digunakan maka semakin kecil nilai PSNR dan semakin besar nilai RMSE-nya. 


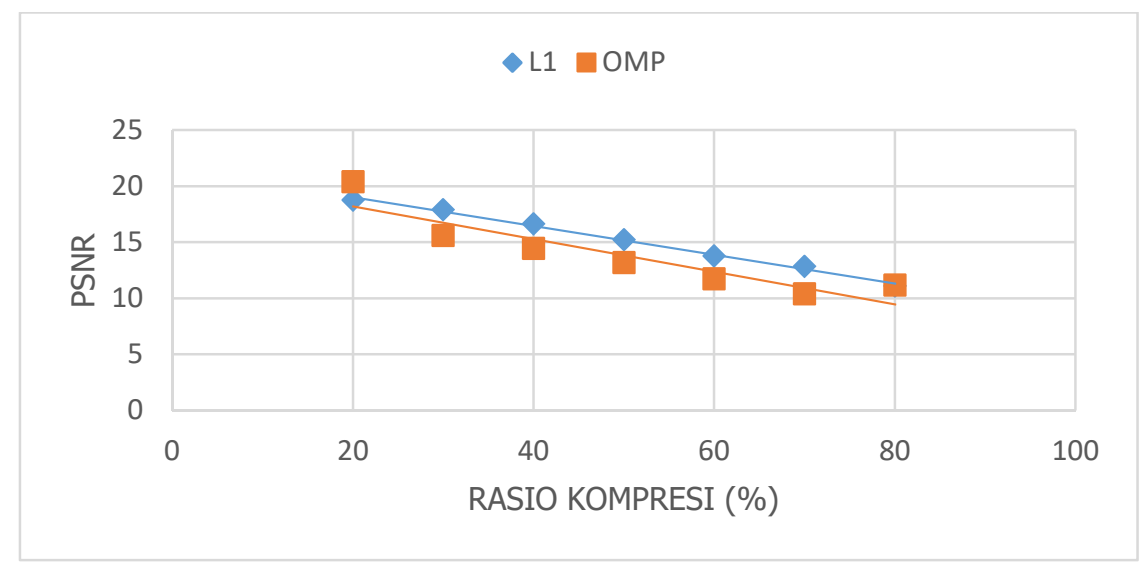

Gambar 10. Perbandingan PSNR pada $\ell_{1}$ dan OMP untuk Rasio Kompresi yang berbedabeda

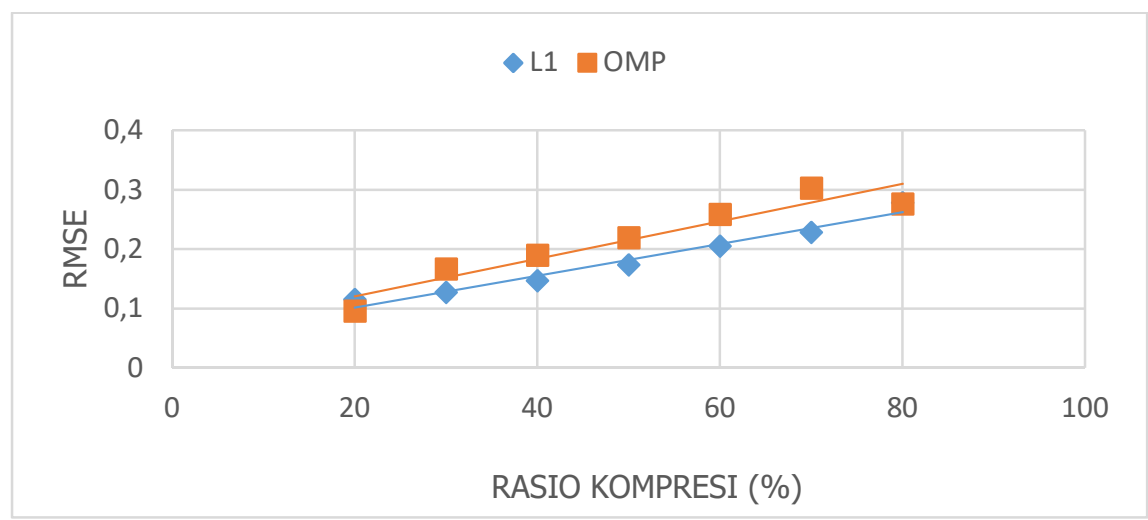

Gambar 11. Perbandingan RMSE pada $\ell_{1}$ dan OMP untuk Rasio Kompresi yang berbedabeda

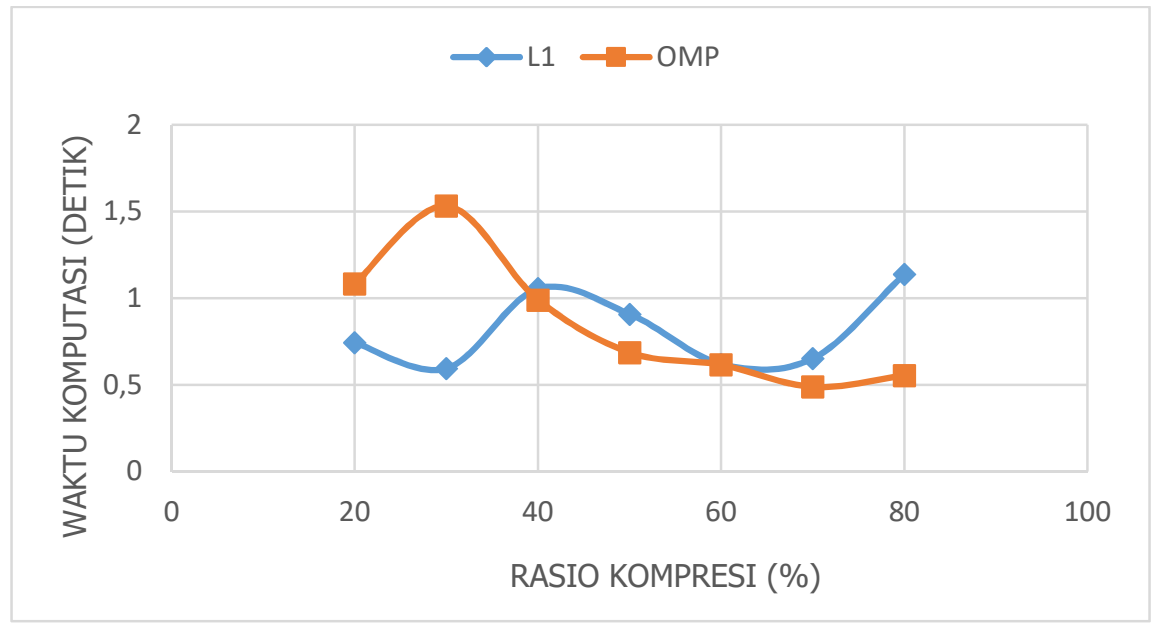

Gambar 12. Perbandingan Waktu Komputasi pada $\ell_{1}$ dan OMP untuk Rasio Kompresi yang berbeda-beda

Dengan mengacu pada Gambar 10-12 di atas, maka algoritma $\ell_{1}$-magic via transformasi sparsitas DCT dapat digunakan pada radar cuaca IWarp. Begitu juga jika menggunakan algoritma OMP via transformasi DCT akan didapatkan hasil performansi yang baik pada rasio kompresi yang rendah. Hal ini terlihat bahwa sinyal beat radar IWarp berhasil dikembalikan 
setelah dilakukan CS walaupun hanya bagus pada rasio kompresi yang kecil. Transformasi DCT dalam hal ini bisa dijadikan transformasi sparsitas yang baik karena terbukti mampu membantu proses CS dan rekonstruksinya, baik dengan menggunakan rekonstruksi $\ell_{1}$-magic maupun dengan menggunakan rekonstruksi OMP. Rekonstruksi dengan menggunakan metode $\ell_{1}$ rata-rata PSNR yang lebih tinggi dibandingkan dengan OMP, hal ini terlihat dari Gambar 10. Seiring dengan PSNR, untuk nilai rata-rata RMSE pada $\ell_{1}$ lebih kecil daripada menggunakan OMP, hal ini terlihat pada Gambar 11.

Pada Gambar 12 menunjukkan bahwa rata-rata waktu komputasi pada $\ell_{1}$ membutuhkan lebih sedikit daripada OMP untuk rasio kompresi rendah sedangkan untuk rasio tinggi $\ell_{1}$ membutuhkan waktu yang lebih lama daripada OMP. Hal ini terjadi karena di saat rasio kompresi rendah, maka pencarian nilai $x$ pada algoritma $\ell_{1}$ memiliki iterasi lebih sedikit. Sedangkan pada saat rasio kompresi tinggi, pencarian nilai $x$ pada algoritma $\ell_{1}$ memiliki iterasi lebih banyak karena memiliki kandidat $x$ yang lebih bervariasi dibandingkan dengan OMP. Sedangkan pada OMP, waktu komputasinya konsisten menurun karena updating akan berhenti jika sistem sudah mendekati suboptimal, sedangkan iterasi pada $\ell_{1}$ benar-benar akan berhenti saat sistem sudah optimal. Jika waktu komputasi masing-masing jenis rekonstruksi tersebut dihitung rataannya, maka didapatkan bahwa rata-rata waktu komputasi untuk $\ell_{1}$ adalah 0.81702 detik sedangkan rata-rata waktu komputasi untuk OMP adalah 0.850832 detik. Oleh karena itu rekomendasi penelitian berikutnya adalah dengan menggunakan rekonstruksi $\ell_{1}$ untuk meningkatkan PSNR, memperkecil RMSE dan mempercepat waktu komputasi. Dengan analisis sementara yang telah dijabarkan pada makalah ini, memiliki keyakinan bahwa teknik ini dapat memberikan peluang penelitian untuk mengembangkan metode CS untuk mempercepat komputasi pada saat akuisisi data pada aplikasi radar cuaca.

\section{KESIMPULAN}

Pada penelitian ini telah dirancang suatu sistem CS pada sinyal beat radar cuaca Iwarp menggunakan DCT dan $\boldsymbol{\ell}_{\mathbf{1}}$-magic dengan performansi yang baik terhadap perubahan rasio kompresi rendah. Rasio kompresi dan jenis rekonstruksi akan berpengaruh terhadap hasil PSNR, RMSE dan waktu komputasi sistem. Semakin tinggi rasio kompresi pada sinyal beat, baik menggunakan $\boldsymbol{\ell}_{\mathbf{1}}$-magic maupun OMP, dengan transformasi sparsitas DCT maka semakin kecil nilai PSNR-nya dan semakin besar nilai RMSE-nya. Jenis rekonstruksi juga memberikan pengaruh terhadap performansi sistem. Pada saat bersamaan dengan bertambahnya rasio kompresi, $\boldsymbol{\ell}_{\mathbf{1}}$-magic memiliki rata-rata PSNR sebesar $15.17801 \mathrm{~dB}$, sedangkan OMP memiliki rata-rata PSNR yang lebih kecil yaitu 13.84319 dB. Rata-rata nilai PSNR pada $\boldsymbol{\ell}_{\mathbf{1}}$-magic terhadap OMP memiliki gap sekitar $2 \mathrm{~dB}$. Rata-rata nilai RMSE untuk $\boldsymbol{\ell}_{1}$-magic via DCT adalah 0.182071 , sedangkan OMP via DCT memiliki rata-rata RMSE yang lebih besar yaitu 0.215414 . Dari segi rata-rata waktu komputasinya, $\boldsymbol{\ell}_{\mathbf{1}}$-magic via DCT memiliki waktu komputasi yang lebih cepat daripada OMP via DCT. Selisih waktu komputasi sebesar 0.034 detik ini akan sangat memberikan pengaruh terhadap lamanya waktu komputasi apabila data yang diolah semakin besar. Pada penelitian berikutnya, ingin mengolah keseluruhan data agar didapatkan produk radar cuaca (reflectivity) dalam satu sapuan penuh dengan menggunakan metode yang diusulkan pada makalah ini. 


\section{DAFTAR RUJUKAN}

Baraniuk, R., \& Steeghs, P. (2007). Compressive radar imaging. IEEE Radar Conference, (pp. 128-133).

Candès , E. J., \& Wakin, M. B. (2008). An introduction to compressive sampling. IEEE Signal Processing Magazine, 25(2), 21-30.

Candès Justin, E. J., Romberg, K., \& Tao, T. (2006). Stable Signal Recovery from Incomplete and Inaccurate Measurements. Communications on Pure and Applied Mathematics, 1207-1223.

Donoho, L. D. (2006). Compressed sensing. IEEE Transactions on Information Theory, 52(4), pp. $1289-1306$.

Doviak, R. J., \& Zrnic, S. D. (1993). Doppler radar and weather observation. Dover Publications, Inc.

Kawami, R., A Hirabayashi, N., Tanaka, M., Shibata, T., Ijiri, T., Shimamura, S., Ushio, T. (2016). 2-dimensional high-quality reconstruction of compressive measurements of phased array weather radar. 2016 Asia-Paci?c Signal and Information Processing Association Annual Summit and Conference (APSIPA), (pp. 1-7).

Kawami, R., Hirabayashi, A., Ijiri, T., Shimamura, S., Kikuchi, H., \& Ushio, T. (2017). 3Dimensional Compressive Sensing and High-Quality Recovery for Phased Array Weather Radar. 2017 International Conference On Sampling Theory And Applications (Sampta), (pp. 658-661).

Kawami, R., Kataoka, H., Kitahara, D., Hirabayashi, A., Ijiri, T., Shimamura, S., . . Ushio, T. (2017). Fast High-Quality Three-Dimensional Reconstruction from Compressive Observation of Phased Array Weather Radar. Proceedings of APSIPA, (pp. 44-49).

Milinkovic , M., \& Petric, D. (2018). Comparison between CS and JPEG in terms of image compression. 7th Mediterranean Conference on Embedded Computing MECO.

Mishra, K. V., Kruger, A., \& Krajewski, W. F. (2014). Compressed sensing applied to weather radar. IEEE Geoscience and Remote Sensing Symposium, (pp. 1832-1835).

Nyquist. (1928). Certain topics in telegraph transmission theory. Transactions of the American Institute of Electrical Engineers, 4オ42), 617-644.

Purnamasari, R., Suksmono, A. B., Edward, I. J., \& Zakia, I. (2018). Recovery of Radar's Beat Signal Based on Compressive Sampling.

Reyes, C., Hilaire, T., Paul, S., \& Mecklenbr"auker, H. F. (2010). Evaluation of the Root Mean Square Error Performance of the PAST-Consensus Algorithm. International ITG Workshop on Smart Antennas. 
Sajjadieh, M. H., \& Asif, A. (2017). Compressive sensing time reversal mimo radar: Joint direction and doppler frequency estimation. IEEE Signal Processing Letters, 22(9), 1283-1287.

Shannon, C. (1949). Communication in the presence of noise. Proceedings of the IRE, 371), 10-21.

Shimamura, S., Kikuchi, H., Matsuda, T., Kim, G., Yoshikawa, E., Nakamura, Y., \& Ushio, T. (2016). Large-Volume Data Compression Using Compressed Sensing for Meteorological Radar. Electronics and Communications in Japan, 99(10), 704-710.

Strang, G. (2006). The discrete cosine transform. SIAM, 41, pp. 135-147.

Suksmono, A. B. (2014). Improved compressive sampling sfcw radar by equipartition of energy sampling. International Journal on Electrical Engineering and Informatics (IJEEI), 6(3). 